\title{
SOBRE AS PRÁTICAS PEDAGÓGICAS NA/DA CRECHE: PERSPECTIVAS DAS PROFISSIONAIS DO MUNICÍPIO DE CORUMBÁ/MS
}

\section{ON PEDAGOGICAL PRACTICES IN / OF THE CRECHE: PROSPECTS OF THE PROFESSIONALS OF THE CITY OF CORUMBÁ / MS}

Ingrid Loraini de Alencar da SILVA ${ }^{1}$

Vanessa de ALMEIDA ${ }^{2}$

Sílvia Adriana RODRIGUES ${ }^{3}$

\begin{abstract}
Resumo: esse artigo discute as concepções de prática pedagógica da creche de profissionais atuantes no município de Corumbá-MS. A pesquisa adotou como instrumento de coleta de informações questionário misto, respondido por 80 profissionais da cidade em questão (51\% do total), cuja análise não nos permitiu afirmar que há práticas pedagógicas de excelência no município. Há um percentual interessante de respostas que indicam passos na direção certa; porém, também aparecem afirmações que indicam que as participantes não compreendem perfeitamente as características infantis, bem como ainda mantêm uma visão assistencialista do papel e função da creche, e consequentemente, do trabalho a ser realizado.
\end{abstract}

Palavras-chave: Creche; prática pedagógica; concepção das profissionais; cuidar e educar.

Abstract: this article discusses the conceptions of pedagogical practice of daycare professionals working in the municipality of Corumbá-MS. The research adopted a mixed questionnaire, answered by 80 professionals from the city in question (51\% of the total), whose analysis did not allow us to affirm that there are pedagogical practices of excellence in the municipality. There is an interesting percentage of responses that indicate steps in the right direction; However, there are also statements that indicate that the participants do not fully understand the characteristics of children, as well as maintain a supportive view of the role and function of the day care center and, consequently, the work to be done

Keywords: Daycare; Pedagogical Practice; Professional design; Caring and educating.

\section{Introdução}

A instituição creche é mais que um espaço destinado a cuidar e educar das crianças

\footnotetext{
${ }^{1}$ Pedagoga; Professora da Rede Municipal de Educação de Corumbá-MS. E-mail: ingridloraini@ yahoo.com.br

2 Pedagoga; Professora da Rede Municipal de Educação de Corumbá-MS. E-mail:

vanessadealmeida657@gmail.com

${ }^{3}$ Professora Adjunta da UFMS - Campus do Pantanal (Pós-Graduação) e Campus de Três Lagoas (Graduação e Pós-Graduação). E-mail: onlysil5@gmail.com
} 


\section{HORIZONTES - REVISTA DE EDUCAÇÃO}

e-ISSN: 2318-1540

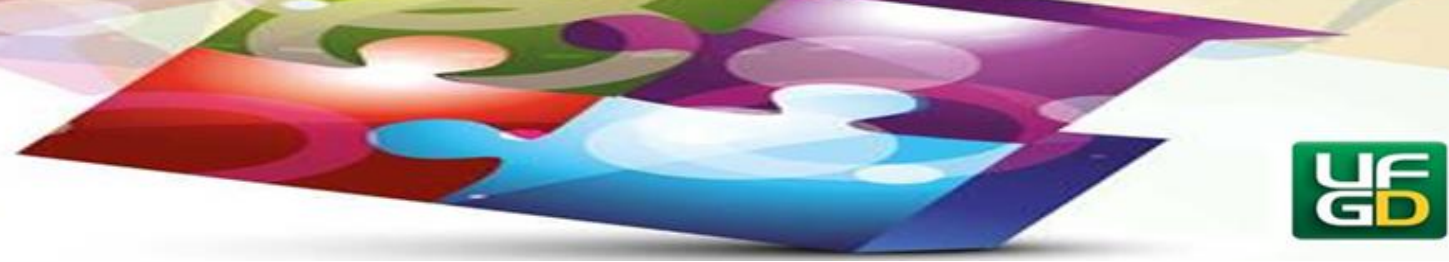

pequenas; trata-se de um direito por elas adquirido com a promulgação da Constituição Federal de 1988, que determinou como dever do Estado garantir um espaço específico para oferecer cuidados e educação para a pequena infância. Acrescenta-se a isso a homologação da Lei de Diretrizes e Bases da Educação Nacional - LDB nº. 9.394/96, o reconhecimento da Educação Infantil (creche e pré-escola) como primeira etapa da educação básica.

Importante ainda lembrar que a Educação Infantil tem como objetivo promover a socialização, o desenvolvimento integral e integrado das crianças, expressa dessa forma nas Diretrizes Nacionais para a Educação Infantil (BRASIL, 2010).

Diante de tais pressupostos, o presente texto apresenta como objetivo refletir sobre as concepções das profissionais das creches do município de Corumbá-MS sobre prática pedagógica. Cabe destacar que a discussão ora apresentada é um recorte de uma pesquisa mais ampla desenvolvida pelo Grupo de Estudos e Pesquisa sobre Infâncias e Educação Infantil (GEPIEI) da Universidade Federal do Mato Grosso do Sul - Campus do Pantanal (UFMS/CPAN), que teve como objetivo geral compreender alguns aspectos do trabalho pedagógico desenvolvido com as crianças de 0 a 3 anos nas creches deste município.

\section{A função da creche e a prática pedagógica dos profissionais}

Partimos do pressuposto de que a creche possibilita às crianças uma vivência social diferente da que estão acostumadas no grupo familiar, uma vez que esse espaço amplia a diversidade e experiência socioculturais. Assim, desempenha um importante papel fundamental, compartilhado com a família, na formação, cuidado e a educação dos pequenos (BECCHI et al., 2012).

Dessa forma, é fundamental que os profissionais que atuam nas instituições de educação infantil compreendam a importância de trabalhar o cuidar e o educar de forma indissociada, percebendo de forma clara o quanto isso contribui para a realização de seu trabalho de forma adequada, uma vez que na relação com as crianças pequenas todas as ações são de cuidado e ao mesmo tempo educativas.

Isso porque, conforme aponta Didonet (2003, p. 9), nas ações cotidianas de cuidados estão imbricados momentos educativos, pois: 


\section{HORIZONTES - REVISTA DE EDUCAÇÃO}

[...] o ato de dar banho, trocar a fralda, vestir e pentear o cabelo são gestos de comunicação humana entre o adulto e o bebê nos quais há uma troca profunda de sentimentos e, portanto, organização mental, de estruturação interior, de formação de autoimagem, do desenvolvimento do 'eu' da criança: o modo como se encara as manifestações de birra, de desagrado, de curiosidade das crianças, como se busca a superação de comportamento de 'agressão' e como se promove a interação social determina o tipo de educação que se está dando a elas: a fala do adulto inicia a criança na linguagem, pois vai dizendo o que ela faz, o que as outras estão fazendo, o que sente e, assim, vai mediando os atos por meio das linguagens. Não há um conteúdo educativo na creche desvinculado dos gestos de cuidar. Não há um ensino, seja um conhecimento, ou um hábito, que utilize uma via diferente da atenção, afetuosa, alegre, disponível e promotora da progressiva autonomia da criança.

Diante desses argumentos é importante apontar que o cotidiano pedagógico da creche é diferente de outros níveis educacionais, pois nesse ambiente, encontram-se crianças bem pequenas, que estão em momento peculiar dos processos de desenvolvimento e aprendizagem, começando a realizar as interações com mundo e consigo mesma.

Assim, é necessário que as atividades propostas sejam significativas para as crianças, bem como respeitem suas individualidades, com uma rotina planejada de acordo com seus interesses e necessidades, proporcionando conhecimento, interação, experiência múltiplas e significativas para as crianças (BECCHI et al., 2012).

A creche é um lugar onde as linguagens infantis estão presentes, sendo importante entender as diferentes formas de expressão dos pequenos, para que não sejam equivocadamente interpretadas. Isso porque o trabalho na creche, que tem como foco a criança, deve permitir a ocorrência de experiências ricas, diversas, lúdicas e com uso de diversas linguagens, no qual possa ter sentido a vida e as aprendizagens infantis (BARBOSA, 2009).

De acordo com Tristão (2005), no cotidiano educativo da creche é preciso ficar atento ao que os pequeninos nos indicam por meio de suas manifestações e "alfabetizar-se nas linguagens dos bebês"; essas são atitudes essenciais a quem realiza trabalhos com crianças pequenas para que se possa respeitar o tempo e as necessidades específicas de cada criança. Ainda conforme a mesma autora:

$\mathrm{O}$ adulto, habituado à linguagem falada, encontra dificuldades para compreender outras formas de comunicação e expressão que, no caso das crianças pequeninas, são os olhares, os gestos, o choro, os sorrisos, os balbucios. Na maioria das vezes, o que ocorre com os profissionais envolvidos é isto: não conseguem perceber esses sinais comunicativos tão complexos (TRISTÃO, 2005, p. 18). 


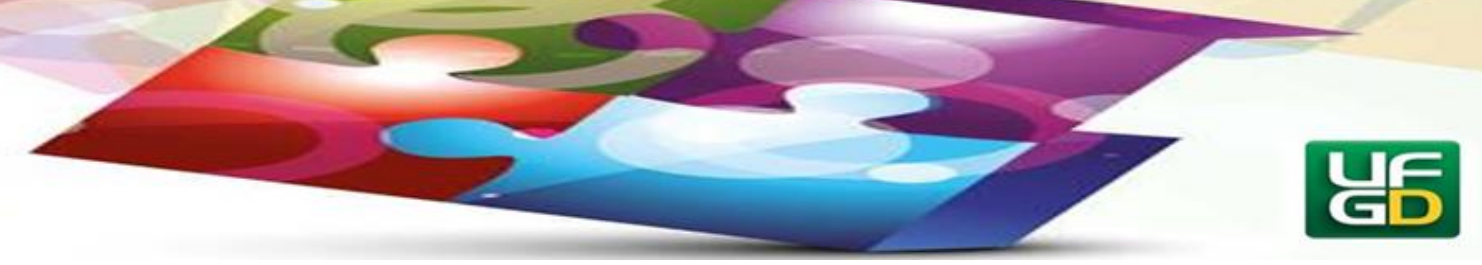

Dessa maneira, o trabalho com múltiplas linguagens na creche permite que as expressões das sensações, dos sentimentos, ideias das crianças pequenas em relação ao mundo, a si mesmas e com as demais crianças e adultos, sendo assim possível compreender o mundo de forma ampla. Entendemos então que as crianças têm a oportunidade de interpretar e se comunicar por meio do corpo, de olhares, gestos, choros, sorrisos, por meio de movimento e expressões que vêm muito antes da linguagem oral e que não é observado pelo adulto (BARBOSA, 2009).

É essencial uma interação rica do adulto com a criança, pois a criança aprende mais significativamente com essa troca comunicativa com o professor e com as demais crianças. Importante salientar que com as crianças bem pequenas esses momentos de troca, de comunicação, são mais férteis quando ocorrem de forma lúdica, evidenciando o valor do brincar, não só como principal forma de linguagem utilizada pelas crianças, mas também como instrumento educativo.

Defender o brincar como elemento da prática pedagógica da creche implica o entendimento deste como processo que oportuniza o desenvolvimento global das crianças, incluindo aprendizagens de diversas naturezas. Isso porque o brincar ou a brincadeira intencionalmente motivada,

[...] fornece ampla estrutura para mudanças das necessidades e consciência, pois nela as crianças ressignificam o que vivem e sentem. [....] também é uma forma particular de comunicação, de prazer, de recreação, espaço onde as crianças podem agir por conta própria, tomar decisões, transgredir, dar novo sentido às coisas (CORSINO, 2006, p. 7).

Cabe então apontar que os professores/educadores desempenham importante papel no momento da brincadeira, pois cabe a eles estimular a atividade mental, social e psicomotora dos pequenos, sempre atentos as suas necessidades, potencialidades e limites; assim, sua presença não deve inibir, bem como sua ausência não deve gerar desconforto e sensação de abandono às crianças (FORTUNA, 2010).

Desse modo, o brincar e a brincadeira devem ser respeitados na Educação Infantil, uma vez que nesse movimento a criança vai dominando expressões culturais tipicamente humanas, experimentando, inventando e criando através do lúdico. Portanto, os espaços e tempos da creche precisam ser planejados de modo a propiciar e convidar para o lúdico, com diferentes 


\section{HORIZONTES - REVISTA DE EDUCAÇÃO}

e-ISSN: 2318-1540

objetos que possam ser manipulados e transformados a partir da brincadeira, elementos, dentre outros, que marcam a especificidade da prática pedagógica da creche (BARBOSA, 2009).

\section{Metodologia e análise dos dados}

No que diz respeito à natureza do objeto do estudo escolhido, a abordagem adotada foi a de caráter quanti-qualitativo; em relação aos objetivos propostos, a pesquisa se caracterizou também como explicativa e descritiva (GONSALVES, 2003; SANTOS, 2004). Ainda sobre o enquadramento da investigação, trata-se de um estudo de caso, uma vez que visamos à descoberta, buscando retratar o contexto a partir de uma interpretação não generalizante (LUDKE; ANDRÉ, 1986).

Para a obtenção dos dados foi utilizado questionário misto, composto por 21 questões, cabendo esclarecer que para a escrita desse artigo foram utilizadas somente três questões que inquiriam os profissionais da creche sobre a prática pedagógica realizada nas instituições. Ainda a título de esclarecimento, tendo em vista os limites do texto, de cada questão serão comentadas apenas as três categorias de respostas que foram mais frequentes.

Na época da coleta dos dados, realizada no ano de 2014, o município contava com 10 creches em funcionamento, com um número total de 155 profissionais atuantes, dentre os quais 85 ocupavam o cargo de docente, 20 de professor auxiliar e 50 eram atendentes. Importante destacar que os dados que serão discutidos foram obtidos com o total de 9 instituições, isso pelo fato de que todos os profissionais de uma das creches se recusaram participar da pesquisa; além destes, outros profissionais de creches diferentes também não aceitaram responder ao questionário. Temos então respostas de um total de 80 profissionais (52\%), sendo eles 50 professores (59\% do total de atuantes); nove (09) professores auxiliares (45\%) e 21 atendentes (42\%) (SILVA; RODRIGUES, 2015).

Conforme já apontado, tendo em vista o objetivo específico de conhecer alguns aspectos da prática pedagógica dos profissionais que trabalham nas creches do município, uma das questões apresentadas no questionário foi: "Como você descreveria o seu dia a dia com os bebês/crianças na creche?".

As respostas ofertadas para essa pergunta foram organizadas em quinze categorias, incluindo um percentual de $3,7 \%$ de respostas consideradas inadequadas. Com o número maior 


\section{HORIZONTES - REVISTA DE EDUCAÇÃO}

de respostas (13\%), temos as que indicaram que o dia a dia na creche com os bebês/crianças é muito agitado. Acreditamos que o cotidiano da creche pode ser entendido como agitado pelo fato da criança pequena ser muito ativa, comunicativa, cheias de emoções, que se movimenta o tempo todo. Diante dos fatos, é necessário que os profissionais planejem atividades e organizem tempos e espaços que explorem essas características e promovam o crescimento integral das crianças.

Além disso, é preciso que os profissionais procurem planejar o tempo das crianças de forma que este tenha certa flexibilidade, procurando trazer para elas certa tranquilidade no dia a dia, respeitando os ritmos de cada criança, organizando uma rotina, que ajude a criança a construir noções de tempo e espaço e assim aprender a se situar no ambiente social (RODRIGUES, 2011).

A segunda categoria com maior número de respostas apontava o cotidiano com os bebês/crianças como momento de aprendizado (11\%). Observamos então que existe o reconhecimento das profissionais de que elas também aprendem com as crianças, o que acreditamos ser muito positivo; pois, conforme enfatiza Kramer (2003), os profissionais têm muito a aprender com as crianças com seu olhar, seus gestos, com a sua linguagem... E para que essas experiências sejam mais ainda enriquecidas é importante que os adultos envolvam na sua prática os conhecimentos e os afetos, atenção, seriedade, cuidado e precisam conhecer as teorias do desenvolvimento, da aprendizagem, da personalidade e incorporá-las na sua prática cotidiana, tendo atitude permanente de investigação.

O terceiro grupo de respostas com número maior considerava o cotidiano da creche como repleto de cuidados $(9,3 \%)$. Acreditamos que tais indicações nos permitem inferir que as profissionais têm uma prática marcada pelo cuidado, determinada por uma visão de certa forma assistencialista do atendimento a ser oferecida na creche; pensamos ainda que tal resposta pode ser relacionada a uma visão de criança como sujeito frágil e incapaz.

Retomamos então o apontamento de que é fundamental o entendimento de que o educar está articulado aos momentos/ações de cuidados, que são processos complementares e indissociáveis no trabalho cotidiano com crianças pequenas. Nesse sentido é necessário que os profissionais construam conhecimentos e habilidades para trabalhar com os pequenos, para que todos os momentos da rotina da creche sejam situações de aprendizagens, que permitam que a criança se desenvolva em todos os aspectos, construa sua autonomia, o conhecimento social e 


\section{HORIZONTES - REVISTA DE EDUCAÇÃO}

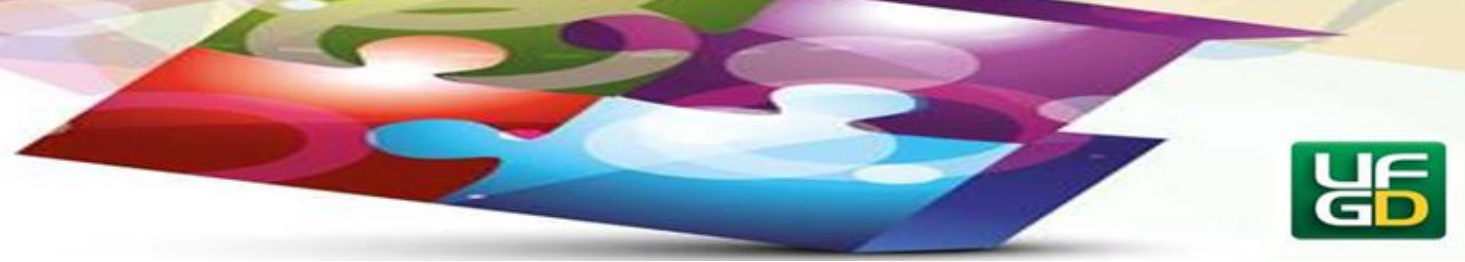

físico; e ainda, que perceba a criança/bebê como sujeito em processo peculiar do desenvolvimento, mas ao mesmo tempo ser completo e capaz dentro de suas singularidades (RODRIGUES, 2015).

Cremos que essa mudança na visão seja necessária para que as professoras compreendam que as crianças não estão na creche apenas para serem atendidas em suas necessidades fisiológicas, uma vez que o objetivo primeiro dessa instituição é promover a socialização; bem como, que elas são capazes de pequenas ações, de se comunicar, se relacionar com os adultos e demais crianças, sendo o cuidar a dimensão fundamental no relacionamento humano e o educar a ferramenta privilegiada para promover a inserção social (TRISTÃO, 2004).

No que diz respeito à segunda questão a ser discutida: "Como você se comunica com os bebês?", as respostas obtidas foram organizadas em dez categorias.

A categoria com maior número de respostas foi a das indicações de que a comunicação com os bebês é feita por meio da linguagem oral (31,2\%). Esta indicação, com este percentual, é de certa forma assustadora; isso porque a maioria das crianças que frequentam a creche está numa faixa etária, que geralmente, não tem o domínio (parcial ou total) da linguagem oral, utilizando-se de outras formas de comunicação (como gestos, olhares, movimentos). Com isso, é essencial que os educadores se utilizem dessas outras linguagens para comunicar com os pequenos, para que não só entendê-los, como também possam ser entendidos por eles em suas intenções comunicativas. Dessa forma, compreendemos que a linguagem oral é importante e os pequenos precisam ser inseridos em contextos e aprendizagem dela. Porém, é essencial que se dê oportunidade para eles se manifestarem com suas linguagens particulares e que estas sejam respeitadas (BARBOSA, 2009).

A segunda categoria dentre as respostas com maior percentual foi a que apontava que a comunicação com os bebês era feita por meio da música $(15,9 \%)$. Consideramos muito relevante essa resposta, pois a música é uma linguagem simbólica (e lúdica) que possibilita às crianças se comunicarem e também extravasar seus sentimentos e suas emoções; além disso, possibilita o desenvolvimento de habilidades como concentração, atenção, memória, percepção auditiva, imaginação, socialização, coordenação motora, entre outras, contribuindo assim para a formação integral da criança (GODOI, 2011). 


\section{HORIZONTES - REVISTA DE EDUCAÇÃO}

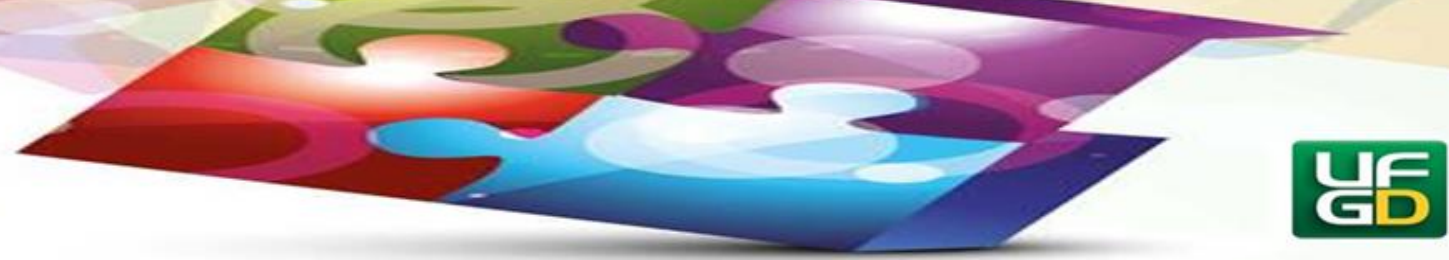

Cremos que essa é uma maneira dos profissionais procurarem ser criativos, trazendo várias experiências, ricas e significativas, que possibilitam, além de situações prazerosas, o desenvolvimento da sensibilidade musical, outras potencialidades e a ampliação dos conhecimentos e visão de mundo, bem como a construção da identidade e autonomia das crianças. (GODOI, 2011).

Referente à terceira categoria de respostas mais frequentes, estão as indicações de comunicação com os bebês por meio dos gestos $(14,4 \%)$. Consideramos muito importante que as profissionais utilizem dos gestos como forma de se comunicar com os bebês, pois é por meio destes, do corpo de uma maneira geral, que a criança estabelece as primeiras relações com o mundo físico e social. Os gestos, as mímicas, os movimentos com o corpo, compõem uma forma peculiar de linguagem das crianças pequenas, uma capacidade específica de expressar sensações, emoções e os conhecimentos em construção a respeito do mundo; sendo então necessário que os profissionais proporcionem tempos e espaços para a criança explorar os movimentos como uma maneira de se comunicar e expressar o que sentem (RICHTER, 2006).

Com relação à terceira questão: "Dentre as tarefas que você realiza todos os dias, quais você considera mais importante para os bebês?”, as respostas foram organizadas em 14 categorias.

A categoria de respostas com maior frequência indicando quais as tarefas mais utilizadas no dia a dia foi as de que promovem a aprendizagem e o desenvolvimento (motor/cognitivo) da criança (20\%). Referente à aprendizagem e ao desenvolvimento, consideramos ser importante valorizar os aspectos motor e cognitivo, elementos valorizados em todas as teorias do desenvolvimento. No entanto, entendemos que o desenvolvimento humano é um processo gradual que envolve também outra dimensão que é a afetiva (RODRIGUES, 2015); assim, em espaços formais de ensino/aprendizagem as crianças/aprendizes não podem ser percebidas de forma cindida, como se estivessem somente evoluindo nos aspectos motor e/ou cognitivo separada de questões emotivas/afetivas; elas precisam ser entendidas e atendidas "por inteiro", sem separar "cabeça” do "corpo" (TRISTÃO, 2004).

$\mathrm{Na}$ segunda categoria de respostas com maior frequência tivemos a indicação de brincadeiras e atividades lúdicas $(14,6 \%)$ como sendo as mais importantes no cotidiano da creche, as quais consideramos bastante pertinente, tendo em vista que para que a criança se desenvolva plenamente ela precisa ter oportunidade de utilizar seu imaginário, de socializar, se 


\section{HORIZONTES - REVISTA DE EDUCAÇÃO}

e-ISSN: 2318-1540

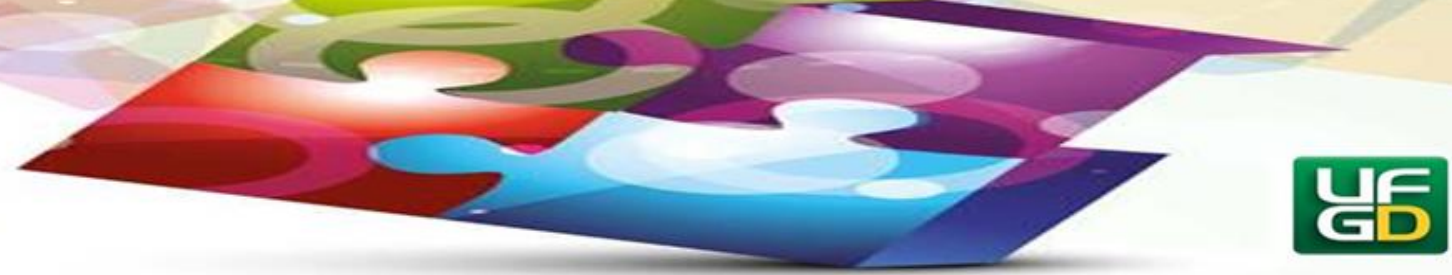

expressar, se comunicar, desenvolver os aspectos emocional, social e mental, que se dão de forma privilegiada no brincar (MALUF, 2003).

$\mathrm{Na}$ brincadeira, a criança consegue explorar o mundo de diversas formas por meio dos objetos, pessoas, natureza e da cultura assim podendo entender o seu entorno (KISHIMOTO, 2010). Torna-se então importante deixar as crianças livres para brincar, sendo necessário que o adulto permita-lhes escolher entre as diversas possibilidades de brincadeiras, enriquecendo suas experiências, com materiais estruturados e não estruturados, ambientes lúdicos internos e/ou ao ar livro (BONDIOLI; GARIBOLDI, 2012).

Por outro lado, cabe observar que brincadeiras e atividades lúdicas aparecem citadas separadas, ou não diretamente relacionadas com a indicação de atividades que promovem aprendizagens e desenvolvimento. Conforme aponta Rodrigues (2016, p. 55), é necessário se apropriar do brincar com o sentido de:

[...] processo que oportuniza o socializar, aprender a negociar para conseguir o que quer, a ganhar e a perder as disputas, a esperar, cooperar e a evoluir no processo de adequado desenvolvimento global. Isso porque, parte-se do princípio de que a brincadeira é sinônimo de aprendizagem em sentido amplo $[\ldots]$.

Cabe então o apontamento de que os dados obtidos podem indicar haver um entendimento equivocado por parte das profissionais participantes da pesquisa, ou ainda, a ausência de entendimento do brincar como elemento constitutivo das práticas pedagógicas cotidianas da Educação infantil conforme indicado nas Diretrizes Curriculares Nacionais para este nível.

$\mathrm{Na}$ terceira categoria mais indicada, as profissionais apontaram todas as atividades $(13,5 \%)$, como sendo importantes para os bebês. Consideramos esta uma resposta paradoxal; se por um lado todas as atividades do cotidiano da creche são de fato importantes, por outro, a indicação genérica pode indicar, na prática, certa displicência com o que deve ser planejado para as crianças pequenas.

Todas as atividades realizadas na creche são muito importantes, por essa razão devem ser intencional e antecipadamente planejadas, sempre pensadas de forma que possibilitem experiências significativas para as crianças, para serem realizadas tanto individual quanto coletivamente. 


\section{HORIZONTES - REVISTA DE EDUCAÇÃO}

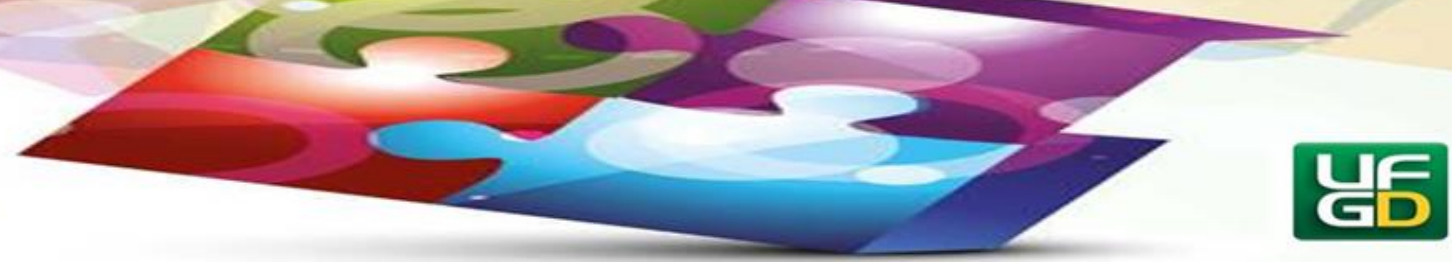

Cabe ainda destacar entre os dados obtidos, tendo em mente o que consideramos ser a função da creche, nos chamou bastante atenção que apenas 5,6\% dos profissionais consideram o cuidar e educar como sendo importantes para os bebês, ou seja, identificando de forma aceitável o que seria a identidade pedagógica da creche.

O cuidar/educar é tarefa fundante do trabalho/ação da creche, pois todos os momentos na creche são momentos de aprendizado e de cuidado, por isso, é importante que em todas as situações vividas na creche sejam entendidas como sendo de cuidado e educação (KRAMER, 2005). Neste sentido, nos atos de cuidar/educar o professor precisa estar atento às necessidades dos pequenos, apoiando-os nos desafios, valorizando cada uma de suas conquistas e suas formas peculiares de pensar e agir; suas tentativas de explorar e compreender o mundo, buscando assim ultrapassar a visão que a criança precisa apenas ser protegida e atendida em suas necessidades fisiológicas básicas como alimentação, sono, higiene (BARBOSA, 2009; RAMOS, 2010).

\section{Considerações finais}

Durante a construção desse artigo, buscamos discutir a importância de se ter uma boa prática pedagógica na creche, e o quanto é importante que o professor compreenda que ele é o responsável não só pelo cuidado, mas também pela aprendizagem e desenvolvimento dos pequenos que ali se encontram.

Cabe então apontar que os dados levantados não nos permitem afirmar que há práticas pedagógicas de excelência nas creches do município de Corumbá-MS. Já que há um percentual interessante de respostas dos profissionais bastante positivas, como por exemplo, considerar que a creche é um lugar de aprendizado (de adultos e crianças), em que é importante o trabalho pedagógico permeado de ludicidade e brincadeiras; que a música e os gestos são formas privilegiadas de se comunicar com os bebês, que indicam passos na direção certa.

No entanto, também aparecem respostas que indicam que os profissionais não compreendem perfeitamente as características infantis, tais como indicar a linguagem oral para se comunicar com os bebês em detrimento de outras linguagens. Retomamos que não desconsideramos a importância de trabalhar com a linguagem oral, afinal de contas os pequenos precisam estar em contato com essa forma de comunicação para que possam compreender e se 


\section{HORIZONTES - REVISTA DE EDUCAÇÃO}

apropriar dela; porém é essencial que os profissionais aprendam e trabalhem com diversos tipos de linguagens com as crianças como os gestos e o brincar.

Importante também reafirmar a importância de trabalhar outros aspectos do desenvolvimento como o afetivo e o social e não só o motor e cognitivo como indicaram algumas profissionais, tendo em vista que é objetivo da educação infantil, principalmente no espaço da creche, promover o desenvolvimento integral e integrado das crianças.

Outro elemento preocupante é a baixa frequência da indicação do cuidar e do educar articulados como tarefa da creche. Acreditamos que essa não percepção se dá tendo em vista que a instituição creche, devido seu histórico, ainda mantém marcas profundas da caridade e do assistencialismo; sendo entendida como local para receber crianças carentes de cuidados e atenção, cujas práticas não precisam de uma intencionalidade pedagógica ou educativa em sentido amplo.

Dessa forma, a presente discussão pretender colaborar com os esforços de promover a superação da visão assistencialista que ainda permeia as práticas da creche e o ideário de um grande número de profissionais que nela atuam e da sociedade de maneira geral. A creche é um espaço educativo, de direito das crianças, um espaço com objetivo de possibilitar a aprendizagem e o desenvolvimento integral e integrado das crianças, tendo a necessidade de que todos profissionais que nela atuam tenham formação pedagógica específica para atuar com os as crianças deste nível.

Nessa direção, conforme assinala Rodrigues (2016, p. 96):

[...] uma das qualidades exigidas da profissão docente é a preocupação com os processos efetivos de ensino, o compromisso ético com o ensinar, que permite ao profissional não ser somente um expectador do processo, como alguém externo, mas como um dos atores deste, tendo em vista que é esta postura, aliada aos saberes que vão sendo construídos que permitirão a reflexão crítica sobre a prática [...].

Para finalizar, reafirmamos a necessidade de que os responsáveis pelo trabalho pedagógico com as crianças nas creches compreendam como acontecem os processos de aprendizagem e desenvolvimento da criança para que ele possa encontrar maneiras mais adequadas de realizar o seu trabalho, entendendo a criança como sujeito de direito, capaz e que merece ser respeitada em todos as suas particularidades, garantindo assim que as crianças, nesse ambiente, vivam a sua infância de forma plena. 


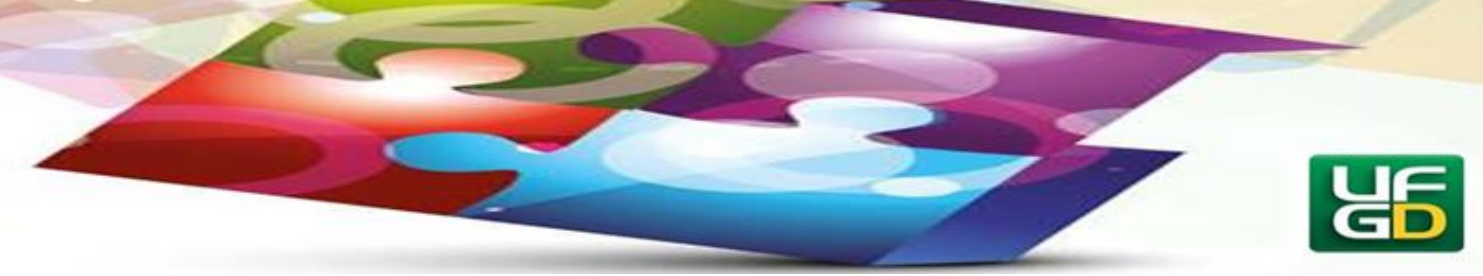

\section{Referências}

BARBOSA, M. C. S. Práticas cotidianas na educação infantil - bases para reflexão sobre as orientações curriculares. Brasília: MEC, 2009.

BECCHI, E. et al. Ideias orientadoras para a creche: a qualidade negociada. Campinas: Autores Associados, 2012.

CORSINO, P. Proposta pedagógica: o cotidiano da Educação Infantil. Salto para o futuro, SEED/MEC, Boletim 23, p. 03-13, nov. 2006.

DIDONET, V. Não há educação sem cuidado. Pátio Educação Infantil, Porto Alegre, n.1, p. 6-9, abr./jul. 2003.

FORTUNA, T. R. O lugar do brincar na Educação Infantil. Pátio Educação Infantil, Porto Alegre, n. 27, p.8-10, abr./jun. 2010.

GONSALVES, E. P. Conversas sobre a iniciação a pesquisa científica. 3. ed. Campinas: Alínea, 2003.

GODOI, L. R. A importância da música na Educação Infantil. Monografia, Universidade Estadual de Londrina, Londrina, 2011.

KRAMER S. De que professores precisamos para a educação infantil? Uma pergunta, várias respostas. Pátio Educação Infantil, Porto Alegre, n. 2, p.10-3, ago./nov. 2003.

KRAMER, S. Profissionais de Educação Infantil: gestão e formação. São Paulo: Ática, 2005.

LUDKE, M.; ANDRÉ, M. E. D. A. Pesquisa em educação: abordagens qualitativas. São Paulo: EPU, 1986.

MALUF, A. C. M. Brincar: prazer e aprendizado. Petrópolis: Vozes, 2003.

OSTETO, L. Planejamento na Educação Infantil: mais que a atividade, a criança em foco. In: OSTETO, L. (org.). Encontros e encantamentos na Educação Infantil. 3.ed. Campinas: Papirus, 2000. p. 175-200.

RAMOS, T. K. G. A criança em interação social no berçário da creche e suas interfaces com a organização do ambiente pedagógico. 2010. Tese (Doutorado em Educação). Universidade Federal de Pernambuco, Recife, 2010.

RICHTER, L. M. Movimento corporal da criança na Educação Infantil: expressão, comunicação e interação. Dissertação (Mestrado em Educação) - Universidade Federal de Uberlândia: Uberlândia, 2006. 


\section{HORIZONTES - REVISTA DE EDUCACÃO}

e-ISSN: 2318-1540

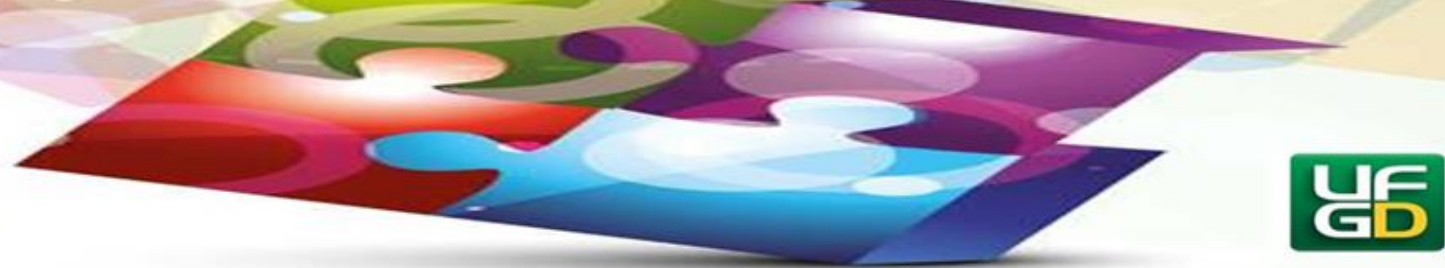

RODRIGUES, S. A. As rotinas e a formação dos enredos pedagógicos na Educação Infantil. In: GARMS, G. M. Z.; RODRIGUES, S. A. (org.). Temas e dilemas pedagógicos da Educação Infantil: desafios e caminhos. Campinas: Mercado das Letras, 2011. p. 91-113.

RODRIGUES, S. A. Tessituras do desenvolvimento humano: Wallon e expressividade afetiva na primeira infância. Campo Grande: Ed. UFMS, 2015.

RODRIGUES, S. A. Viajando pela educação da primeiríssima infância: sentidos, crenças e valores que sustentam os saberes e as práticas pedagógicas na/da creche. 2016. 253f. Tese (Doutorado em Educação) - Universidade Estadual Paulista, Faculdade de Ciências e Tecnologia, Presidente Prudente, 2016.

SANTOS, A. R. Metodologia científica: a construção do conhecimento. 6. ed. Rio de Janeiro: DP\&A, 2004.

SILVA, F. C.; RODRIGUES, S. A. Trabalho docente na Educação Infantil: o perfil dos profissionais do município de Corumbá-MS. In: ENCONTRO DE POLÍTICAS E PRÁTICAS DE FORMAÇÃO DE PROFESSORES, 6. 2015. Anais on line. Campo Grande MS: UEMS, 2015. v. 1. p. 229-243.

TRISTÃO, F. C. D. Ser professora de bebês: um estudo de caso em uma creche conveniada. Dissertação (Mestrado em Educação) - Programa de Pós-Graduação em Educação, Universidade Federal de Santa Catarina, Florianópolis, 2004.

Enviado: 28/05/2019.

Aceito: $17 / 07 / 2019$ 